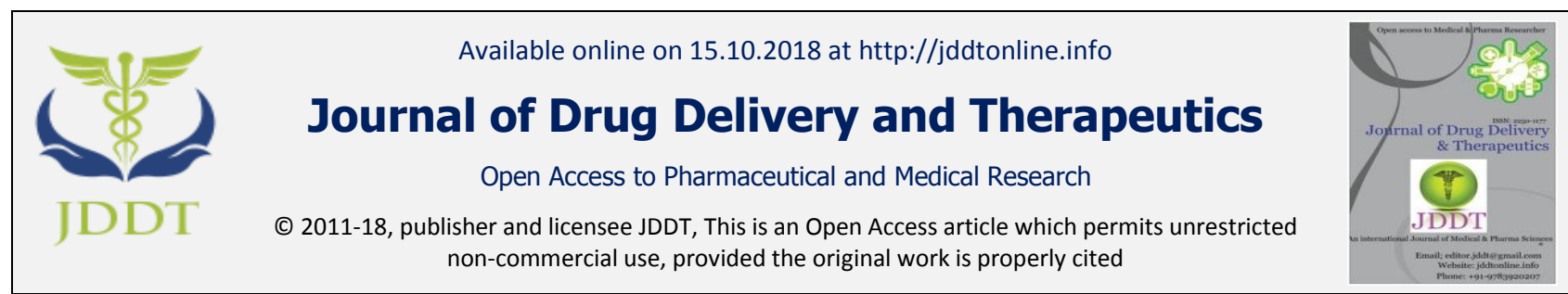

Open $\odot$ Access

Review Article

\title{
FLOATING TABLETS AND ITS POLYMERS
}

\author{
Shaika Saadia Zubedi, Shahid Mohammed* \\ Department of Pharmaceutics, Deccan School of Pharmacy, Hyderabad-500001
}

\begin{abstract}
Oral drug delivery system is the most preferred route of administration for drug delivery. In the development of the drug delivery system many components play important role. Polymers are amongst those components which have evolved with the drug delivery system. Polymers are the macromolecule compound containing many monomer units joined to each other by bonds. The floating drug delivery systems (FDDS) become an additional advantage for drugs that are absorbed primarily in the upper segments of gastrointestinal (GI) tract, i.e., the stomach, duodenum and jejunum. The purpose of writing this review on floating drug delivery systems (FDDS) was to focus on the types of floating drug delivery systems, principal and mechanism of floatation to achieve gastric retention and polymers used in floating Drug delivery systems. Polymers used in the drug delivery system are of two types Natural and Synthetic based on their origin. Both types of the polymers have some advantages and disadvantages. This particular article gives information about the different types of natural and synthetic polymer used in the drug delivery system. Natural polymers like guar gum, chitosan, xanthan gum, Gellan gum and sodium alginate are mentioned in the article. Synthetic polymers mentioned are HPMC, Eudragit, and Ethylcellulose.
\end{abstract}

Keywords: Floating Drug Delivery System, Polymers, Natural gums, HPMC.

Article Info: Received 21 Aug, 2018; Review Completed 24 Sep 2018; Accepted 25 Sep 2018; Available online 15 Oct 2018

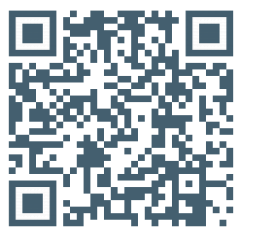

Cite this article as:

Zubedi SS, Mohammed S, Floating tablets and its polymers, Journal of Drug Delivery and Therapeutics. 2018; 8(5-s):16-24 DOI: http://dx.doi.org/10.22270/jddt.v8i5-s.1928

*Address for Correspondence:

Shahid Mohammed, Department of Pharmaceutics, Deccan School of Pharmacy, Hyderabad-500001

\section{I.INTRODUCTION}

Oral administration is the most convenient and preferred means of any drug delivery to the systematic circulation. Oral controlled release drug delivery have recently been of increasing interest in pharmaceutical field to achieve improved therapeutic advantages, such as ease of dosing administration, patient compliance and flexibility in formulation. Drugs that are easily absorbed from gastrointestinal tract (GIT) and have short half-lives are eliminated quickly from the systemic circulation. Frequent dosing of these drugs is required to achieve suitable therapeutic activity. To avoid this limitation, the development of oral sustained-controlled release formulations is an attempt to release the drug slowly into the gastrointestinal tract (GIT) and maintain an effective drug concentration in the systemic circulation for a long time. After oral administration, such a drug delivery would be retained in the stomach and release the drug in a controlled manner, so that the drug could be supplied continuously to its absorption sites in the gastrointestinal tract (GIT) ${ }^{1}$. To formulate a site-specific orally administered controlled release dosage form, it is desirable to achieve a prolong gastric residence time by the drug delivery. Prolonged gastric retention improves bioavailability, increases the duration of drug release, reduces drug waste, and improves the drug solubility that are less soluble in a high $\mathrm{pH}$ environment ${ }^{2}$. Also prolonged gastric retention time (GRT) in the stomach could be advantageous for local action in the upper part of the small intestine e.g. treatment of peptic ulcer, etc.

Gastroretentive drug delivery is an approach to prolong gastric residence time, thereby targeting site-specific drug release in the upper gastrointestinal tract (GIT) for local or systemic effects. This elongated retention ability provides more benefits which may be enumerated as: improving activity span for short half-life drugs, 
bioavailability of drugs, exclusion of side effects, reduction in dosage periodicity, saving drugs owing to former benefit, improves solubility for drugs that are less soluble in a high $\mathrm{pH}$ environment, optimized therapy and ultimately easy compliance on the part of the patient ${ }^{3,4}$. Over the last few decades, several gastroretentive drug delivery approaches being designed and developed, including: high density (sinking) systems that is retained in the bottom of the stomach 5 , low density (floating) systems that causes buoyancy in gastric fluid 6, 7, 8, mucoadhesive systems that causes bioadhesion to stomach mucosa ${ }^{9}$, unfoldable, extendible, or swellable systems which limits emptying of the dosage forms through the pyloric sphincter of stomach 10, 11, super porous hydrogel systems, magnetic systems etc.

It is widely acknowledged that the extent of gastrointestinal tract drug absorption is related to contact time with the small intestinal mucosa ${ }^{12,13}$. Thus small intestinal transit time is an important parameter for drugs that are incompletely absorbed.

\subsection{FLOATING DRUG DELIVERY SYSTEM}

Floating drug delivery system is also known as hydrodynamically balanced system (HBS). While the system is floating on the gastric contents, the drug is released slowly at the desired rate from the system. After release of the drug, the residual system is emptied from the stomach. This results in an increased GRT and a better control of the fluctuations in plasma drug concentration $^{14}$.

\subsection{APPLICATIONS OF FLOATING DRUG DELIVERY SYSTEM}

Floating drug delivery offers several applications for drugs having poor bioavailability because of the narrow absorption window in the upper part of the gastrointestinal tract. It retains the dosage form at the site of absorption and thus enhances the bioavailability. These are summarized as follows.

\section{Sustained Drug Delivery}

HBS systems can remain in the stomach for long periods and hence can release the drug over a prolonged period of time. The problem of short gastric residence time encountered with an oral CR formulation hence can be overcome with these systems. These systems have a bulk density of $<1$ as a result of which they can float on the gastric contents. These systems are relatively large in size and passing from the pyloric opening is prohibited. Recently sustained release floating capsules of nicardipine hydrochloride were developed and were evaluated in vivo. The formulation compared with commercially available MICARD capsules using rabbits. Plasma concentration time curves showed a longer duration for administration (16 hours) in the sustained release floating capsules as compared with conventional MICARD capsules ( 8 hours) ${ }^{15}$.

Similarly a comparative study ${ }^{16}$ between the Madopar HBS and Madopar standard formulation was done and it was shown that the drug was released up to 8 hours in vitro in the former case and the release was essentially complete in less than 30 minutes in the latter case.

\section{Site-Specific Drug Delivery}

These systems are particularly advantageous for drugs that are specifically absorbed from stomach or the proximal part of the small intestine, eg, riboflavin and furosemide. Furosemide is primarily absorbed from the stomach followed by the duodenum. It has been reported that a monolithic floating dosage form with prolonged gastric residence time was developed and the bioavailability was increased. AUC obtained with the floating tablets was approximately 1.8 times those of conventional furosemide tablets ${ }^{17}$.

A bilayer-floating capsule was developed for local delivery of misoprostol, which is a synthetic analog of prostaglandin E1 used as a protectant of gastric ulcers caused by administration of NSAIDs. By targeting slow delivery of misoprostol to the stomach, desired therapeutic levels could be achieved and drug waste could be reduced ${ }^{18}$.

\section{Absorption Enhancement}

Drugs that have poor bioavailability because of site specific absorption from the upper part of the gastrointestinal tract are potential candidates to be formulated as floating drug delivery systems, thereby maximizing their absorption. A significant increase in the bioavailability of floating dosage forms (42.9\%) could be achieved as compared with commercially available LASIX tablets $(33.4 \%)$ and enteric coated LASIX-long product $(29.5 \%){ }^{17}$.

Table 1: Commercially available floating Formulations ${ }^{37}$

\begin{tabular}{|l|l|l|l|}
\hline Name of the product & Active Ingredient & Category & Name of Company \\
\hline $\begin{array}{l}\text { Madopar } \\
\text { Capsule HBS }\end{array}$ & $\begin{array}{l}\text { Levodopa }(100 \mathrm{mg}) \\
\text { and Benserazide }(25 \mathrm{mg})\end{array}$ & Anti-parkinsonial & Roche, USA \\
\hline Valrelease $\circledast$ Capsule & Diazepam $(15 \mathrm{mg})$ & Anti-anxiety & Hoffmann-La Roche, USA \\
\hline Liquid Gaviscon & $\begin{array}{l}\text { Al hydroxide }(95 \mathrm{mg}) . \\
\text { Mg carbonate }(358 \mathrm{mg})\end{array}$ & $\begin{array}{l}\text { Antacid (in reflux } \\
\text { esophagitis) }\end{array}$ & Glaxo Smithkline, India \\
\hline Cytotec Bilayer capsule & Misoprostol $(100 \mathrm{mcg} / 200 \mathrm{mcg})$ & - & Pharmacia, USA \\
\hline Topalkan ${ }^{\circledR}$ & $\begin{array}{l}\text { Alginic acid, Aluminium and } \\
\text { Magnesium salts }\end{array}$ & Antacid & Pierre Fabre Drug, Frabce \\
\hline Almagate flowcoat & Al-Mg antacid & Antacid & Ranbaxy, India \\
\hline
\end{tabular}




\subsection{CLASSIFICATION OF FLOATING DRUG DELIVERY SYSTEM}

1. Single Unit Floating Dosage Systems

a) Effervescent Systems (Gas-generating Systems)

b) Non-effervescent Systems

2. Multiple Unit Floating Dosage Systems

a) Non-effervescent Systems

b) Effervescent Systems (Gas-generating Systems)

c) Hollow Microspheres

d) Raft Forming Systems.

\section{Single Unit Floating Dosage Systems}

\section{a) Effervescent Systems (Gas-generating Systems):}

These buoyant systems utilized matrices that are prepared with swellable polymers like HPMC, polysaccharides like chitosan, effervescent components such as sodium bicarbonate, citric acid and tartaric acid or chambers containing a liquid that gasifies at body temperature. The optimal stoichiometric ratio of citric acid and sodium bicarbonate for gas generation is reported to be $0.76: 1$. The common approach for preparing these systems involves resin beads loaded with bicarbonate and coated with ethylcellulose. The coating, which is insoluble but permeable, allows permeation of water. Thus, carbon dioxide is released, causing the beads to float in the stomach (Fig: 4). Excipients used most commonly in these systems include HPMC, polyacrylate polymers, polyvinyl acetate, Carbopol®, agar, sodium alginate, calcium chloride, polyethylene oxide and polycarbonates ${ }^{19}$.

\section{b) Non-Effervescent Systems:}

This type of system, after swallowing, swells unrestrained via imbibitions of gastric fluid to an extent that it prevents their exit from the stomach. These systems may be referred as "plug-type systems" since they have a tendency to remain lodged near the pyloric sphincter. One of the formulation methods of such dosage forms involves the mixing of drug with a gel, which in contact with gastric fluid swells. The air trapped by the swollen polymer confers buoyancy to these dosage forms. Examples of this type of FDDS include colloidal gel barrier, micro porous compartment system, alginate beads, and hollow microspheres.

Another type is a Fluid filled floating chamber which includes incorporation of a gas-filled floatation chamber into a micro porous component that houses a drug reservoir. Apertures or openings are present at the top and bottom walls through which the gastrointestinal tract fluid enters to dissolve the drug. The other two walls in contact with the fluid are sealed so that the undissolved drug remains therein. The fluid present could be air, under partial vacuum or any other suitable gas, liquid, or solid having an appropriate specific gravity and an inert behaviour. The device is of swellable size, remains afloat within the stomach for a prolonged period of time and after the complete release the shell disintegrates, passes off to the intestine, and is eliminated.
A newer self-correcting floatable asymmetric configuration drug delivery system has a 3- layer matrix to control the drug release. This 3-layer principle has been improved by development of an asymmetric configuration drug delivery system in order to modulate the release extent and achieve zero-order release kinetics by initially maintaining a constant area at the diffusing front with subsequent dissolution/erosion toward the completion of the release process. The system was designed in such a manner that it floated to prolong gastric residence time in vivo, resulting in longer total transit time within the gastrointestinal tract environment with maximum absorptive capacity and consequently greater bioavailability.

This particular characteristic would be applicable to drugs that have $\mathrm{pH}$-dependent solubility, a narrow window of absorption, and are absorbed by active transport from either the proximal or distal portion of the small intestine ${ }^{19,20}$.

\section{Multiple Unit Floating Systems:}

In spite of extensive research and development in hydro dynamically balanced systems and other floating tablets, these systems has an important drawback of high variability of gastrointestinal transit time, when orally administered, because of their all-or nothing gastric emptying nature. In order to overcome this problem, multiple unit floating systems were developed, which reduces the inter-subject variability in absorption and lowers the probability of dose- dumping (Fig: 1).

Reports have been found on the development of both non-effervescent and effervescent multiple unit systems. Much research has been focused and the scientists are still exploring the field of hollow microspheres, capable of floating on the gastric fluid and having improved gastric retention properties ${ }^{21}$.

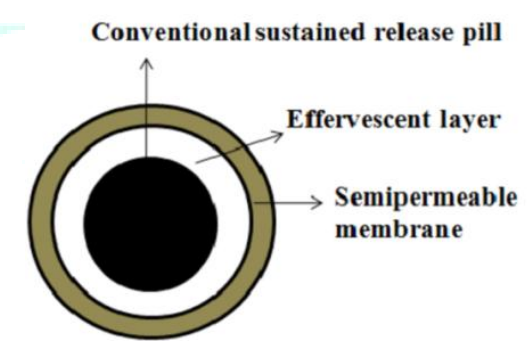

Figure 1: Multiple unit of oral FDDS

\section{a) Non-effervescent Systems:}

Not much report was found in the literature on noneffervescent multiple unit systems, as compared to the effervescent systems. However, few workers have reported the possibility of developing such system containing indomethacin, using chitosan as the polymeric excipient. A multiple unit HBS containing indomethacin as a model drug prepared by the extrusion process is reported. A mixture of drug, chitosan and acetic acid is extruded through a needle, and the extrudate is cut and dried. Chitosan hydrates and floats in the acidic media, \& the required drug release could be obtained by modifying the drug-polymer ratio ${ }^{22}$. 


\section{b) Effervescent Systems (Gas-generating Systems):}

There are reports of sustained release floating granules containing Tetracycline Hcl. The granules are a mixture of drug granulates of two stages i.e. A and B, of which $\mathrm{A}$ contains 60 parts of HPMC, 40 parts of polyacrylic acid and 20 parts of drug and B contains 70 parts of sodium bicarbonate and 30 parts of tartaric acid. 60 parts by weight of granules of stage A and 30 parts by weight of granules of stage B are mixed along with a lubricant and filled into capsule. In dissolution media, the capsule shell dissolves and liberates the granules, which showed a floating time of more than $8 \mathrm{~h}$ and sustained drug release of $80 \%$ in about $6.5 \mathrm{~h}$. Floating minicapsules of pepstatin having a diameter of 0.1-0.2 $\mathrm{mm}$ has been reported. These minicapsules contain a central core and a coating. The central core consists of a granules composed of sodium bicarbonate, lactose and a binder, which is coated with HPMC polymer. Pepstatin is coated on the top of the HPMC layer. The system floats because of the release of $\mathrm{CO}_{2}$ in gastric fluid and the pepstatin resides in the stomach for prolonged period. Alginates have received much attention in the development of multiple unit systems ${ }^{23}$.

\section{c) Hollow Microspheres:}

These are considered as one of the most promising buoyant systems, as they possess the unique advantages of multiple unit systems as well as better floating properties, because of the central hollow space inside the microsphere. The general techniques involved in their preparation include simple solvent evaporation method and solvent diffusion and evaporation method (Fig: 2). The drug release and better floating properties mainly depends upon the type of polymer, plasticizer and the solvents employed for the formulation. Polymers such as Polycarbonate, Eudragit $\AA$, and Cellulose acetate were used in the preparation of hollow microspheres, and the drug release can be modulated by optimizing the polymer-plasticizer ratio and the polymer quantity. Sustained release floating microspheres using polycarbonate were developed, using solvent evaporation technique. Aspirin, Griseofulvin and pnitroaniline were used as model drugs ${ }^{24}$.
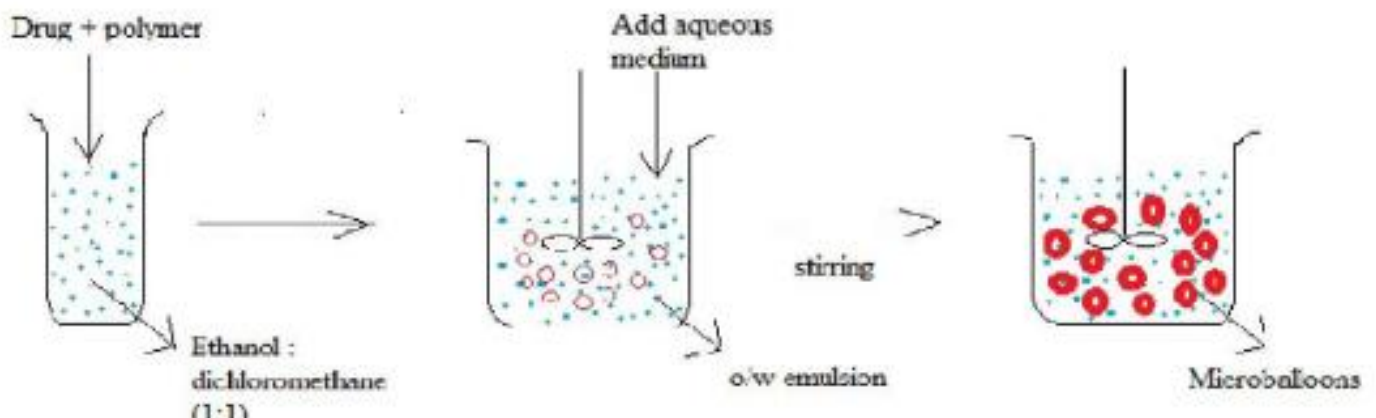

Figure 2: Preparation of Hollow Microspheres

\section{d) Raft Forming Systems:}

Raft forming systems have received much attention for the delivery of antacids and drug delivery for GI infections and disorders. The basic mechanism involved in the raft formation includes the formation of viscous cohesive gel in contact with the gastric fluids, wherein each portion of the liquid swells forming a continuous layer called a raft (Fig: 3 ). The raft floats because of the buoyancy created by the formation of $\mathrm{CO} 2$ and act as a barrier to prevent the reflux of gastric contents like $\mathrm{HCl}$ and enzymes into the oesophagus. Usually, the system contains a gel forming agent and alkaline bicarbonates or carbonates responsible for the formation to make the system less dense and float on the gastric fluids ${ }^{25}$.

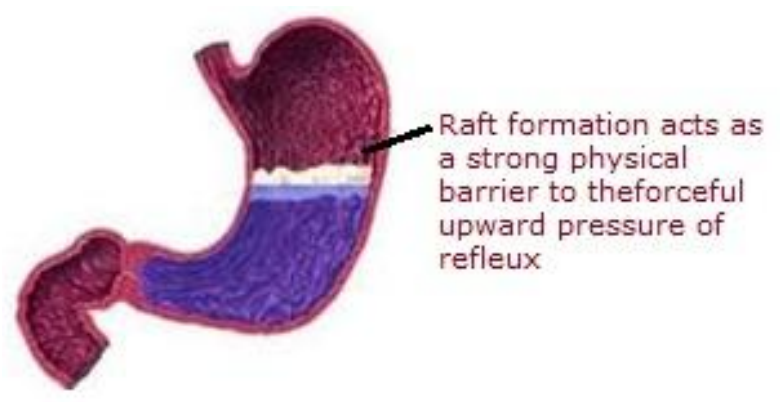

Figure 3: Raft forming system

\subsection{MECHANISM OF FLOATING DRUG DELIVERY SYSTEM}

Floating drug delivery systems (FDDS) have a bulk density less than gastric fluids and so remain buoyant in the stomach without affecting the gastric emptying rate for a prolonged period of time. While the system is floating on the gastric contents (Fig: 4) the drug is released slowly at the desired rate from the system. After release of drug, the residual system is emptied from the stomach. This results in an increased GRT and a better control of the fluctuations in plasma drug concentration.

However, besides a minimal gastric content needed to allow the proper achievement of the buoyancy retention principle, a minimal level of floating force $(F)$ is also required to keep the dosage form reliably buoyant on the surface of the meal. To measure the floating force kinetics, a novel apparatus for determination of resultant weight has been reported in the literature. The apparatus operates by measuring continuously the force equivalent to $F$ (as a function of time) that is required to maintain the submerged object.

The object floats better if $\mathrm{F}$ is on the higher positive side. This apparatus helps in optimizing FDDS with respect to stability and durability of floating forces produced in order to prevent the drawbacks of 
unforeseeable intra-gastric buoyancy capability variations $^{25}$.

$$
\mathrm{F}=\mathrm{F}_{\text {buoyancy }}-\mathrm{F}_{\text {gravity }}=(\mathrm{Df}-\mathrm{Ds}) \mathrm{gV}
$$

Where, $\mathrm{F}=$ total vertical force, $\mathrm{Df}=$ fluid density, $\mathrm{Ds}=$ object density, $\mathrm{V}=$ volume and $\mathrm{g}=$ acceleration due to gravity.

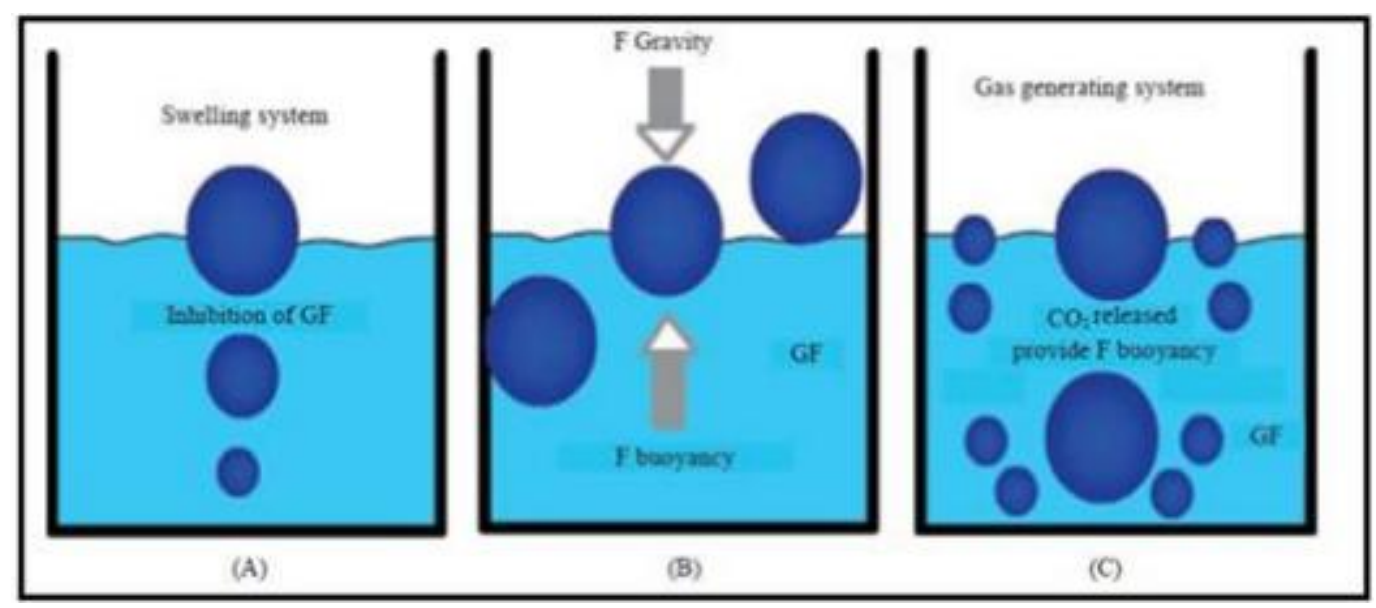

Figure 4: Mechanism of Floating Drug Delivery System

\subsection{POLYMERS USED IN FLOATING DRUG DELIVERY SYSTEM}

Polymers are used in floating system so as to target the drug delivery at specific region in the GI tract i.e. stomach. Both synthetic and natural polymers are used in the floating drug delivery. Natural polymers used in floating system are Guar gum, Chitosan, xanthan gum, Gellan gum, Sodium alginate, etc. Synthetic polymers used for the floating drug delivery are HPMC, Eudragit, ethyl cellulose, etc. ${ }^{26}$.

\subsubsection{Natural Polymers}

Natural gums (obtained from plants) are hydrophilic carbohydrate polymer of high molecular weight. They are generally insoluble in organic solvents, like hydrocarbon, ether. Gums either water soluble or absorb water and swell up or disperse in cold water to give a viscous solution or jelly.

Table 2: List of natural polymer

\begin{tabular}{|l|l|l|}
\hline S.no & Polymer & Source \\
\hline 1 & Guar gum & Endosperm of seed of cynopsis tetragonolobus \\
\hline 2 & Chitosan & Shell of marine invertibrates \\
\hline 3 & Xanthum gum & Fermentation of glucose by Xanthomonas compestris \\
\hline 4 & Gellan gum & Pseudomonas elodea \\
\hline 5 & Sodium alginate & Laminaria hyperboria \\
\hline
\end{tabular}

Natural polymer has advantages over synthetic polymer. They are as follows:

- Biodegradable

- Biocompatible and non-toxic.

- Low cost.

- Environment friendly

- Local availability.

Natural polymer has some disadvantages. They are as follows:

- Microbial contamination

- Batch to batch variation

- Uncontrolled rate of hydration

- Reduced viscosity on storage 27

\section{Guar gum}

Guar gum is naturally occurring galactomannan polysaccharide. Guar gum hydrates and swellsin cold water forming viscous colloidal dispersions or sols. This gelling property retard the drug release and make it a flexible carrier for extended release Dosage forms ${ }^{26}$. In pharmaceutical guar gum is used as disintegrant and as a polymer in floating drug delivery system.

Properties of guar gum:

- It is soluble in water but insoluble in organic solvents.

- Strong hydrogen bond property.

- Excellent thickening, emulsion, film forming property.

- Ability to control rheology. 
Advantages of guar gum in floating drug delivery system:

It has been reported that polymer swelling play an important role in the pattern and amount of drug release. It was found that guar gum formulations were relatively insensitive to stirring speed during in vitro drug dissolution testing and dissolution profile was not affected significantly ${ }^{28}$.

\section{Chitosan}

Chitosan is natural polymer obtainer by deacetylation of chitin. It has favorable biological properties such as nontoxic, biodegrable, biocompatible. It is a bioadhesive polymer and has anti-bacterial properties thus make it suitable for site specific delivery. Chitosan is high molecular weight polycationic weak base with pka value of 6.2-7. On addition to acidic $\mathrm{pH}$ of 1.2 or neutral media it become buoyant in nature and provide control release ${ }^{26}$. By increasing thickness of chitosan film release rate can be decreased ${ }^{28}$.

Advantages of chitosan:

- It forms film that reduces effect of gastrointestinal transit time.

- Hallow microcapsule tend to float on gastric fluid for about $12 \mathrm{hrs}$.

- Release rate of drug followed zero order kinetics ${ }^{28}$.

\section{Xanthan gum}

Xanthan gum is a high molecular weight extracellular polysaccharide produced by pure culture aerobic fermentation of carbohydrate. Xanthan is a long chained polysaccharide with large number of trisaccharide side chains. Gum also has an excellent solubility and stability under acidic and alkaline conditions and in the presence of salts and resists common enzymes.

Advantages of Xanthan gum:

- It is used to increase or decrease rate of release of drug from formulation

- Soluble in water

- High viscosity at low concentration

- It has potential advantage of drug release at zero order kinetics.

Some tablet containing xanthan gum and citric acid show buoyancy for more than $24 \mathrm{hrs}$.

\section{Gellan gum}

Gellan gum is an anionic, high molecular weight, deacetylated extracellular, linear polysaccharide. This gum has an outstanding flavor release, high gel strength, an excellent stability, process flexibility, high clarity, good film former and thermally reversible gel characteristics ${ }^{26}$. Gellan gum is produced as a fermentation product from spingomonas elodea.

Advantages of Gellan gum:

- It has excellent flavor release, high gel strength, and excellent stability.

- It forms gel when positively charged ions are added
- It is used in food product as thickening agent or stabilizing agent ${ }^{[28]}$.

\section{Sodium alginate}

Sodium alginate consists chiefly of the sodium salt of alginic acid, which is a mixture of polyuronic acids composed of residues of d'mannuronic acid and L guluronic acid. The block structure and molecular weight of sodium alginate Samples have been investigated.

- Typical Properties: Acidity/alkalinity ph-7.2 (1\% w/v aqueous solution).

- Solubility: Practically insoluble in ethanol (95\%), ether, chloroform, and ethanol/water mixtures in which the ethanol content is greater than $30 \%$. Also, practically insoluble in other organic Solvents and aqueous acidic solutions in which the ph is less than 3. Slowly soluble in water, forming a viscous colloidal Solution.

- Viscosity (dynamic): Various grades of sodium alginate are commercially available that yield aqueous solutions of varying Viscosity. Typically, a $1 \% \mathrm{w} / \mathrm{v}$ aqueous solution, at $208 \mathrm{C}$, will have a viscosity of 20-400mpa s (20-400cp). Viscosity may vary depending upon concentration, $\mathrm{pH}$, temperature, or the Presence of metal ions. Above $\mathrm{pH} 10$, viscosity decreases ${ }^{29}$.

\subsubsection{Synthetic Polymers}

Synthetic polymers are becoming increasingly important in pharmaceuticals. Uses of synthetic polymer are as binder, film coating agent, etc. Polymer are macromolecule having very large, contain a variety of functional group. Synthetic polymers are either purely synthetic or they are modified form of natural polymer know as semi-synthetic. List of synthetic polymer used is as follows:

1. Hydroxypropyl methyl cellulose

2. Eudragit

3. Ethyl cellulose

Disadvantages of synthetic polymer are as follows

- High cost toxicity environmental pollution

- $\quad$ Acute and chronic adverse effect

- Poor biocompatible

- Inflammatory response and local reaction ${ }^{27}$.

\section{Hydroxypropyl methyl cellulose}

Hydroxypropyl methylcellulose ethers belong to an extensive family of white to off-white, odorless, water soluble polymers that bind, retain water, thicken, form films, lubricate. It is a semi synthetic, inert, viscoelastic polymer, used as an excipient and controlled-delivery component in oral medicaments, found in a variety of commercial products.

Synonyms: Hypromellose, Methocel, Metolose, Pharmacoat, Benecel MHPC, E464 etc. 


\section{Functional category:}

Bioadhesive material, coating agent, controlled-release agent, dispersing agent, dissolution enhancer, emulsifying agent, emulsion stabilizer, extended-release agent, film-forming agent, foaming agent, granulation aid, modified-release agent, mucoadhesive, releasemodifying agent, solubilizing agent, stabilizing agent, suspending agent, sustained release agent, tablet binder, thickening agent, viscosity-increasing agent ${ }^{30}$.

General properties common to the Hypremellose are listed below. Individual type exhibits these properties to varying degrees and may have additional properties that are desirable for specific applications.

- Apparent density: $0.25 \sim 0.70 \mathrm{~g} / \mathrm{cm}^{3}$

- $\quad$ The refractive index $=1.336$

- Surface tension: 42 to $56 \mathrm{mn} / \mathrm{m}$

Solubility: Soluble in cold water, forming a viscous colloidal solution; practically insoluble in hot water, chloroform, ethanol (95\%), and ether, but soluble in mixtures of ethanol and dichloromethane, mixtures of methanol and dichloromethane, and mixtures of water and alcohol. Certain grades of HPMC are soluble in aqueous acetone solutions, mixtures of dichloromethane and propan-2-ol, and other organic solvents. Some grades are swellable in ethanol ${ }^{31}$.

\section{Applications:}

$\checkmark \quad$ In oral products, HPMC is primarily used as a tablet binder, in film-coating, and as a matrix for use in extended release tablet formulations. Concentrations between $2 \%$ and $5 \% \mathrm{w} / \mathrm{w}$ may be used as a binder in either wet- or dry-granulation processes. High viscosity grades may be used to retard the release of drugs from a matrix at levels of $10-80 \% \mathrm{w} / \mathrm{w}$ in tablets and capsules ${ }^{30}$.

$\checkmark$ Hypromellose is also used in liquid oral dosage forms as a suspending and/or thickening agent at concentrations ranging from $0.25-5.0 \%$.

$\checkmark$ Depending upon the viscosity grade, concentrations of $2-20 \% \mathrm{w} / \mathrm{w}$ are used for film-forming solutions to film-coat tablets. Lower viscosity grades are used in aqueous film-coating solutions, while higherviscosity grades are used with organic solvents. Examples of film coating materials that are commercially available include Any Coat C, Spectracel, Pharmacoat, and the Methocel E Premium LV series.

$\checkmark$ Hypromellose is also used as a suspending and thickening agent in topical formulations.

$\checkmark$ Hypromellose at concentrations between $0.45-1.0 \%$ $\mathrm{w} / \mathrm{w}$ may be added as a thickening agent to vehicles for eye drops and artificial tear solutions. It is also used commercially in liquid nasal formulations at a concentration of $0.1 \%$.

$\checkmark$ Hypromellose is used as an emulsifier, suspending agent, and stabilizing agent in topical gels and ointments.

\section{Advantages}

- Water soluble and most abundant polymer in nature

- Used as a thickener, film former and water retension agent

- Hydrophilic matrix is the simplest sustained release technology for oral dosage form ${ }^{[32]}$.

\section{Eudragit}

Nonproprietary names: BP: Acidum methacrylicum et methylis methacrylas polymerisatum 1:2 USPNF: Methacrylic acid copolymer

Synonyms: Polymeric methacrylates.

Functional category: Film former; tablet binder; tablet diluent

\section{Description:}

Polymethacrylates are synthetic cationic and anionic polymers of dimethylaminoethyl methacrylates, methacrylic acid, and methacrylic acid esters in varying ratios. Several different types are commercially available and may be obtained as the dry powder, as an aqueous dispersion, or as an organic solution. A (60: 40) mixture of acetone and propan-2-ol is most commonly used as the organic solvent. Eudragit S 100 is available as powder and solvents used for this is $95 \%$ Acetone and alcohols which is soluble in intestinal fluid from $\mathrm{pH} 7$ and used as an enteric coating material.

Eudragit $\mathrm{L}$ and $\mathrm{S}$ also referred to as methacrylic acid copolymers in the USPNF 23 monograph, are anionic copolymerization products of methacrylic acid and methyl methacrylate. The ratio of free carboxyl groups to the ester is approximately 1:1 in Eudragit L (Type A) and approximately 1: 2 in Eudragit S (Type B). Both polymers are readily soluble in neutral to weakly alkaline conditions ( $\mathrm{pH} 6-7$ ) and form salts with alkalis, thus affording film coats that are resistant to gastric media but soluble in intestinal fluid. Eudragit L100 and Eudragit S-100 are white free-flowing powders with at least $95 \%$ of dry polymers.

\section{Incompatibilities:}

Incompatibilities occur with certain polymethacrylate dispersions depending upon the ionic and physical properties of the polymer and solvent. For example, coagulation may be caused by soluble electrolytes, $\mathrm{pH}$ changes, some organic solvents, and extremes of temperature; Interactions between polymethacrylates and some drugs can occur, although solid polymethacrylates and organic solutions are generally more compatible than aqueous dispersions.

\section{Applications:}

Polymethacrylates (Eudragit) are primarily used in oral capsule and tablet formulations as film-coating agents. Depending on the type of polymer used, films of different solubility characteristics can be produced. Eudragit S 100 is soluble in acetone and alcohols and $1 \mathrm{~N}$ $\mathrm{NaOH}$. In contrast, Eudragit L, S and FS types are used as enteric coating agents because they are resistant to gastric fluid. Different types of enteric coatings are 
soluble at different $\mathrm{pH}$ values: e.g. Eudragit $\mathrm{L}$ is soluble at $\mathrm{pH}>6$ whereas, Eudragit $\mathrm{S}$ and $\mathrm{FS}$ are soluble at $\mathrm{pH}$ $>7$. The $\mathrm{S}$ grade is generally used for coating tablets, while the flexible FS $30 \mathrm{D}$ dispersion is preferred for coating particles.

Eudragit RL, RS, NE 30D, NE 40D and NM30D are used to form water-insoluble film coats for sustained release products. Eudragit RL films are more permeable than those of Eudragit RS, and films of varying permeability can be obtained by mixing the two types together. Polymethacrylates are also used as binders in both aqueous and organic wet-granulation processes. Larger quantities (5-20\%) of dry polymer are used to control the release of an active substance from a tablet matrix. Solid polymers may be used in direct compression processes in quantities of $10-50 \%$. Polymethacrylates polymers may additionally be used to form the matrix layers of transdermal delivery systems and have also been used to prepare novel gel formulations for rectal administration ${ }^{29}$.

\section{Ethyl cellulose}

Ethocel (Ethylcellulose polymers) has been widely used in the pharmaceutical industry for over 50 years. Ethylcellulose has been used for choice in pharmaceutical formulations for various purposes, such as taste-masking of bitter actives, moisture protection, stabilizer, extended release multiparticulate coating, micro-encapsulation of actives, extended release binder in inert matrix systems, solvent and extrusion granulation.

Solubility: Ethylcellulose is a water insoluble cellulose ether, which is prepared from cellulose, it is a partly Oethylated cellulose, its ethoxy content (- OC2H5) is between $44-51 \%$. . It is insoluble at any $\mathrm{pH}$ that occurs in organism, but in the presence of the gastric Juice it undergoes swelling. It is then permeable for water and permits extended modified drug release. This makes it suitable for improved patient compliance.

\section{Applications:}

The application of EC in wet extrusion processes is limited, since the polymer has considerable elastic properties, but can be successfully used as matrix former in combination with some plasticizing agents. The potential of coarse Ethylcellulose (CPEC) and fine particle Ethylcellulose (FPEC) as diluent with high molecular weight polyethylene oxide (PEO), which was used as an extrusion aid and a binder have shown that water is sufficient to prepare a wet granulation product when using FPEC. MCC was included in formulations to contribute its plasticity to the wetted mass during extrusion and to the extrudate during spheronization.
Ethylcellulose is an ideal polymer for the formation of products allowing modified drug release. A small number of Ethylcellulose polymers have been approved for general pharmaceutical application and are used in extended release solid dosage formulations. Several types of such Ethylcellulose exist, e.g. Ethocel 4, Ethocel 10 and Ethocel 45, which differ in the length of the polymer chains, the rate of dissolution, and the viscosity of their solution. Ethylcellulose is suitable to prepare MR coatings ${ }^{33}$.

\subsection{LIMITATIONS/DISADVANTAGES OF FDDS:}

1. These systems require a high level of fluid in the stomach for drug delivery to float and work efficiently-coat.

2. Not suitable for drugs that have solubility or stability problem in GIT.

3. Drugs such as Nifedipine which is well absorbed along the entire GIT and which undergoes first pass metabolism, may not be desirable

4. Drugs which are irritant to gastric mucosa are also not desirable or suitable.

5. The drug substances that are unstable in the acidic environment of the stomach are not suitable candidates to be incorporated in the systems.

6. The dosage form should be administered with a full glass of water (200-250 ml).

7. These systems do not offer significant advantages over the conventional dosage forms for drugs, which are absorbed throughout the gastrointestinal tract $^{34,35,36}$.

\section{CONCLUSION}

The FDDS become an additional advantage for drugs that are absorbed primarily in the upper segments of GI tract, i.e., the stomach, duodenum and jejunum. Polymers are used for the purpose of the controlled release of drug from dosage form. Polymers are the substances which are being used in the formulations for many reasons like gelling agents, emulsifying agents, viscosity increasing agents, rate retarding agents etc. Therefore knowledge of the polymer in field of the drug delivery plays an important role. However a lot of work is still needed to be done to overcome the different physiological and pharmaceutical barriers to develop the more effective dosage forms. It is suggested that future research work in the FDDSs should be aimed at discovering means to accurately control the drug input rate into the GI tract for the optimization of the pharmacokinetic and toxicological profiles of medicinal agents. 


\section{REFERENCES}

1. Streubel A, Siepmann J, Bodmeier R. Gastroretentive drug delivery system. Expert Opin Drug Deliv 2006; 3(2):217- 33.

2. Garg R, Gupta GD. Progress in controlled gastroretentive delivery systems. Trop. J Pharm Res 2008; 7(3):1055-66.

3. Dixit N: Floating drug delivery system. Journal of Current Pharmaceutical Research 2011; 7:6-20.

4. Badoni A, Gnanarajan $\mathrm{G}$ and Ojha A: Review on gastro retentive drug delivery system. The Pharma Innovation 2012; 1:32-42.

5. Rouge N, Allemann E, Gex-Fabry M, Balant L, Cole ET, Buri P, Doelker E. Comparative pharmacokinetic study of a floating multiple-unit capsule, a high density multipleunit capsule and an immediate-release tab containing $25 \mathrm{mg}$ atenolol. Pharm Acta Helbetiae 1998; 73:81-7.

6. Streubel A, Siepmann J, Bodmeier R. Multiple unit Gastroretentive drug delivery: a new preparation method for low density microparticles. J Microencapsul 2003; 20:329-47.

7. Goole J, Vanderbist F, Aruighi K. Development and evaluation of new multiple-unit levodopa sustained-release floating dosage forms. Int J Pharm 2007; 334:35-41.

8. Shrma S, Pawar A. Low density multiparticulate system for pulsatile release of meloxicam. Int J Pharm 2006; 313:150-58.

9. Santus G, Lazzarini G, Bottoni G, Sandefer EP, Page RC, Doll WJ, Ryo UY, Digenis GA. An in vitro- in vivo investigation of oral bioadhesive controlled release furosemide formulations. Eur J Pharm Biopharm 1997; 44:39-52.

10. Klausner EA, Lavy E, Friedman M, Hoffman A. Expandable gastroretentive dosage forms. J Control Release 2003; 90:14362.

11. Deshpande AA, Shah N, Rhodes CT, Malik W. Development of a novel controlled-release system for gastric retention. Pharm Res 1997; 14:815-19.

12. Chandel A, Chauhan K et al., Floating drug delivery systems: A better approach, International Current Pharmaceutical Journal 2012, 1(5):110-118.

13. Hirtz $\mathbf{J}$, The gastrointestinal absorption of drugs in man: a review of current concepts and methods of investigation, $\mathrm{Br} \mathrm{J}$ Clin Pharmacol, 1985, 19:77S-83S.

14. Nayak AK, Maji R, Das B. Gastroretentive Drug Delivery Systems: A Review. Asian Journal of Pharmaceutical and Clinical Research 2010; 3(1):2-9.

15. Moursy NM, Afifi NN, Ghorab DM, El-Saharty Y. Formulation and evaluation of sustained release floating capsules of Nicardipine hydrochloride. Pharmazie. 2003; 58:38Y43.

16. Erni W, Held K. The hydrodynamically balanced system: a novel principle of controlled drug release. Eur Neurol. 1987; 27:215Y275.

17. Menon A, Ritschel WA, Sakr A. Development and evaluation of a monolithic floating dosage form for furosemide. J Pharm Sci. 1994; 83:239Y245.

18. Oth M, Franz M, Timmermans J, Moes A. The bilayer floating capsule: a stomach directed drug delivery system for misoprostal. Pharm Res. 1992; 9:298Y302.
19. Rubinstein A, Friend D.R, Specific delivery to the gastrointestinal tract, in: Domb A. J (Ed.), Polymeric Site Specific Pharmacotherapy, Wiley, Chichester, 1994, 282-283.

20. Desai S. A Novel Floating Controlled Release Drug Delivery System Based on a Dried Gel Matrix Network [master's thesis]. NY, St John's University, 1984 Jamaica.

21. Iannuccelli V, Copp G, Sansone R, Ferolla G, Air compartment multiple-unit system for prolonged gastric residence part II in-vivo evaluation, International Journal of Pharmaceutics 1998; 174:55-62.

22. Tardi P, Troy H, (2002) European patent no.EP1432402

23. Gholap SB, Banarjee SK, Gaikwad DD, Jadhav SL, Thorat R M, Hollow microspheres: A Review, International Journal of pharma science research 2010; 1 (1):74-79.

24. Paterson RS, Omahony B, Eccleston GM, Stevens HNE, Fost er J, Murray JG, An assessment of floating raft formation in a man using magnetic resonance imaging, Journal of Pharm Pharmacol, 2008; 8(1).

25. Mayavanshi AV and Gajjar SS: Floating drug delivery system to increase gastric retention of drugs: A review. Research Journal of Pharmaceutical Technology 2008; 1(4):345-48.

26. Kumar, G. Natural Polymers in the Development of Floating Drug Delivery Systems: A Review. Int. J. Pharm. Life Sci., 2013; 2(4):165-178.

27. Darekar D. An overview on natural gum and its pharmaceutical application. International journal of universal pharmacy and biosciences, December, 2013; 2:535-547. DOI: 10.1016/j.biomag.2014.02.001.

28. Singh, A. kumar. Role of Natural Polymers Used In Floating Drug Delivery System Floating Drug Delivery System. J. Pharm. Sci. Innov, June, 2012; 1:11-15.

29. Raymond R, Sheskey P. Pharmaceutical press. Handbook of Pharmaceutical Excipient Sixth Edition, 2009.

30. Milanovic J., Manojlovic V., Levic S., Rajic N., Nedovic V. \& Bugarski B. Microencapsulation of Flavors in Carnauba Wax. Sensors, 2010; 10:901-912.

31. Sanderson GR. Polysaccharides in Foods. Food Technology, $1981 ; 35,50-56$.

32. Phadtare D, Phadtare G, Asawat M. Hypromellose - A Choice of Polymer In Extended. World journal of pharmacy and pharmaceutical sciences, 2014; 3(9):551-566.

33. Hegyesi, D. Study of the Widely Used Ethylcellulose Polymer as Film Forming and Matrix Former Ph. D. Thesis Diána Hegyesi Pharmacist, 2016.

34. Gopalakrishnan S, Chenthilnathan A. Floating drug delivery system: A review. Journal of Pharmaceutical Science and Technology 2011; 3(2):548-54.

35. Vedha H, Chaudhary J: The recent developments on gastric floating drug delivery system: An overview. Journal of Pharmaceutical Technology and Research 2010; 2(1):524-34.

36. Arunachalam A and Kishan GK: Floating drug delivery system: A review. International Journal of Research in Pharmaceutical Sciences 2011; 2(1):76-83.

37. Jain SK, Jain NK, Agrawal GP. Gastroretentive floating drug delivery: An overview. Drug Deliv Technol 2005; 5:7-15. 